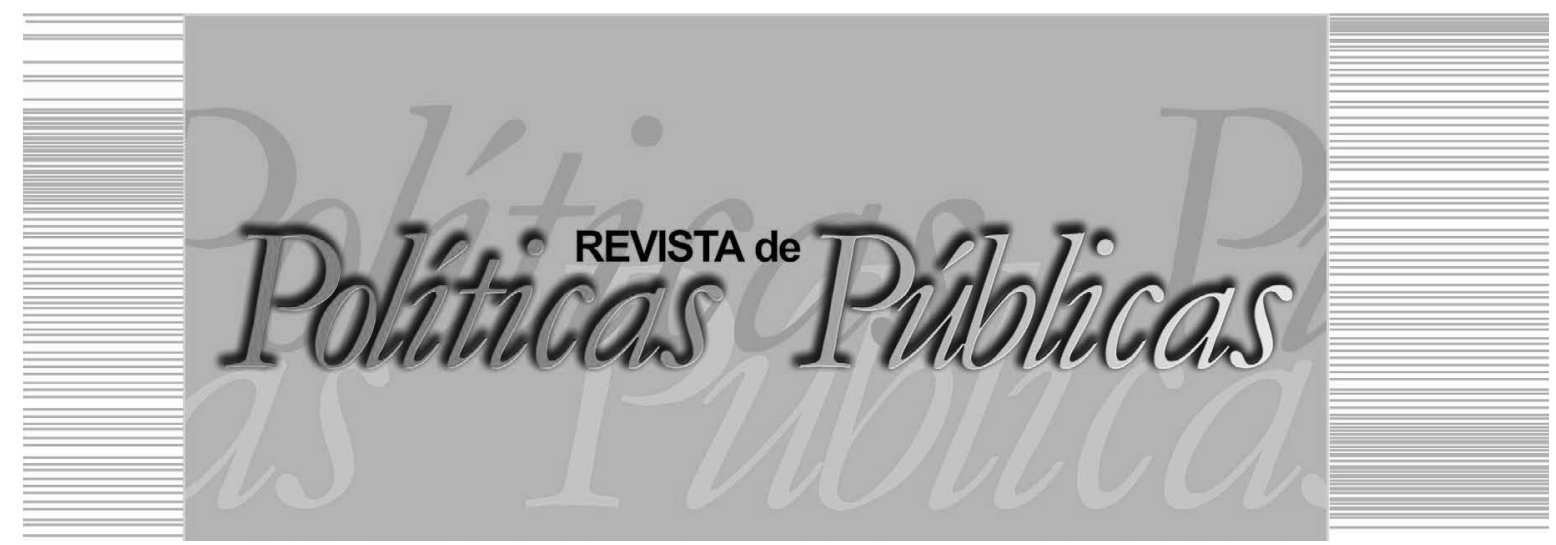

\title{
CONDIÇÕES DE TRABALHO E SAÚDE DE ASSISTENTES SOCIAIS NO ÂMBITO DAS POLITICAS PÚBLICAS
}

\author{
Iana Vasconcelos ${ }^{1}$ \\ Sâmya Rodrigues Ramos ${ }^{2}$ \\ Aione Maria Costa Sousa ${ }^{3}$ \\ Kleylenda Linhares Silva ${ }^{4}$ \\ Aline Câmara Macedo Gracindo ${ }^{5}$
}

\section{Resumo}

O contexto brasileiro contemporâneo, marcado pela reestruturação do capital, impulsiona alterações nas políticas públicas e nas demandas postas às/aos assistentes sociais, bem como nas condições de trabalho, o que repercute na saúde destas/es. Assim, o artigo apresenta resultados de uma pesquisa sobre a situa-

1 Assistente Social, Doutora em Ciências da Saúde pela Universidade Federal do Rio Grande do Norte (UFRN), Professora da Universidade do Estado do Rio Grande do Norte (UERN). E-mail: ianavasconcelos@bol.com.br

2 Assistente Social, Doutora em Serviço Social pela Universidade Federal de Pernambuco (UFPE), Professora da UERN. E-mail: samyarr@uol.com.br

3 Assistente Social, Doutora em Serviço Social e Direitos Sociais pela UFPE, Professora da UERN. E-mail: aionesousa@hotmail.com

4 Assistente Social, Mestre em Serviço Social pela UFRN, Preceptora da Universidade Potiguar (UNP) e Professora da Faculdade Católica Nossa Senhora das Vitórias (FCNSV). E-mail: kleylenda@hotmail.com / Universidade Potiguar - UNP: Av. João da Escóssia, 1561, Nova Betânia - Mossoró/RN. CEP: 59.607-330. Faculdade Católica Nossa Senhora das Vitórias - FCNSV: Rua Doutor Luis Carlos, n. 3439, Novo Horizonte, Açu-RN, CEP: 59650-000.

5 Assistente Social. E-mail:gracindoaline@gmail.com / Universidade do Estado do Rio Grande do Norte - UERN: Rua Almino Afonso, 478 - Centro - Mossoró/RN. CEP: $59.610-210$ 
Iana Vasconcelos | Sâmya Rodrigues Ramos | Aione Maria da Costa Sousa

Kleylenda Linhares da Silva $\mid$ Aline Câmara Macêdo Gracindo

ção das/os egressas/os do curso de Serviço Social da Universidade do Estado do Rio Grande do Norte no mercado de trabalho. Enfatiza as análises acerca das condições de trabalho e saúde desses profissionais. Os resultados reforçam que a/o assistente social convive com determinações impostas pela limitação dos recursos institucionais necessários à efetivação dos processos de trabalho coletivos. Além disso, conclui que o mercado de trabalho para esta categoria é marcado por ampla utilização de formas instáveis de contratação, baixos salários e adversidades em termos de condições de trabalho e saúde.

Palavras-chave: Serviço Social, condições de trabalho, saúde.

\title{
WORK AND HEALTH CONDITIONS OF SOCIAL WORKERS IN THE PUBLIC POLICIES CONTEXT
}

\begin{abstract}
The contemporary Brazilian context, marked by the capital restructuring, drives changes in public policies and the demands put to the social workers, as well in the work conditions, which affects the health of these professionals. Thus, the article presents results of a research about the situation of the graduates in Social Work course of the State University of Rio Grande do Norte in the job market. This article emphasizes the analysis of work and health conditions of these professionals. The results reinforce that the social worker lives with imposed determinations by limitation of institutional resources necessary to implement the collective work processes. Moreover, the job market for this category is marked by extensive use of unstable forms of employment, low wages and adversities in terms of work and health conditions.
\end{abstract}

Key words: Social Work, work conditions, health.

\section{Introdução}

As transformações econômicas, políticas, sociais e culturais impulsionadas pela reestruturação capitalista ${ }^{1}$ geram rebatimentos nas condições de vida e de trabalho, bem como na organização política da classe trabalhadora; por conseguinte, desencadeiam mudanças nas diversas profissões. Ademais, essa conjuntura, marcada pela incessante busca de redução dos custos com a força de trabalho e pelo alargamento da privatização e mercantilização das políticas públicas, dissemina desemprego estrutural, desconstrução dos direitos, assim como repercute na saúde das/os trabalhadoras/es. Portanto, "O capital é em sua estrutura e em seu movimento contemporâneo patogênico para a humanidade." (PAIVA; COSTA, 2016, p. 64).

Esse processo mundial, difundido no contexto brasileiro a partir dos anos 1990, provoca influxos no trabalho das/os assisten- 
tes sociais ao intensificar a exploração e alienação subjacentes às relações de compra e venda de sua força de trabalho, as/os quais se deparam com novas demandas impulsionadas pelo aprofundamento das expressões da questão social, concomitante à desresponsabilização do Estado no tocante à efetivação das políticas públicas e garantia dos direitos sociais. Nesse contexto, o conhecimento acerca das mudanças no mercado de trabalho é fundamental para identificar/ enfrentar os desafios contemporâneos e elaborar respostas qualificadas às demandas que se apresentam no cotidiano dos espaços socioinstitucionais.

Nessa perspectiva, realizamos uma pesquisa com o objetivo de analisar a situação das/os egressas/os do curso de Serviço Social da Universidade do Estado do Rio Grande do Norte (UERN) no mercado de trabalho, apreendendo as demandas, as condições de trabalho e a materialização do projeto profissional.

Para tanto, realizamos pesquisa bibliográfica e de campo. Conseguimos contatar com 187 de um total de 243 egressas/os, graduadas/os entre 2007 e 2012, período delimitado para a pesquisa. Destas/es, 79 nos responderam, enviando contatos de e-mails para o recebimento dos questionários, das/os quais, 40 nos retornaram. Dentre estas/es, 2 afirmaram estar desempregadas/os, 11 disseram estar trabalhando em outras áreas e 27 atuando como assistente social. Fundamentados nas informações coletadas, realizamos a análise dos dados e, para fins de construção deste artigo, enfatizamos as análises acerca das condições de trabalho e saúde das/os profissionais.

\section{CONDIÇÕES DE tRABALHO E SAÚDE DE ASSISTENTES SOCIAIS EGRESSAS/OS DA UERN}

A análise acerca do trabalho de assistentes sociais demanda considerar as relações de assalariamento que permeiam sua inserção no mercado de trabalho, as quais impõem determinações às condições de vida, trabalho e saúde de tais sujeitos. É imprescindível ressaltar, portanto, que o contexto societário contemporâneo, marcado pela reestruturação do capital, alicerçado na redefinição dos processos de gestão e organização do trabalho e do modelo de atuação do Estado, impulsiona alterações nas demandas postas à profissão, bem como nas condições e relações de trabalho nas quais o exercício profissional se efetiva. 
Iana Vasconcelos | Sâmya Rodrigues Ramos | Aione Maria da Costa Sousa

Kleylenda Linhares da Silva $\mid$ Aline Câmara Macêdo Gracindo

Em meio a este processo, pautado na intensa exploração da força de trabalho, os vínculos empregatícios tendem a ser flexibilizados e os recursos necessários à intervenção profissional - fundamentais para garantir a qualidade dos serviços no âmbito das políticas públicas - são precarizados. Dessa forma, "[...] o assistente social, que é chamado a implementar e viabilizar direitos sociais e os meios de exercê-los, se vê tolhido em suas ações que dependem de recursos, condições e meios de trabalho cada vez mais escassos para as políticas e serviços sociais públicos.” (IAMAMOTO, 2006, p. 176).

Essa condição de assalariamento traz profundas implicações para a atuação profissional, haja vista que as/os assistentes sociais não detêm todos os meios necessários à objetivação do seu trabalho. De acordo com Raichelis (2011, p. 428, grifos da autora)

[...] ainda que o Serviço Social tenha sido reconhecido como "profissão liberal" nos estatutos legais e éticos que definem a autonomia teórico-metodológica, técnica e ético-política na condução do exercício profissional, o trabalho do assistente social é tensionado pela relação de compra e venda da sua força de trabalho especializada. A condição de trabalhador assalariado - seja nas instituições públicas ou nos espaços empresariais e privados "sem fins lucrativos", faz com que os profissionais não disponham nem tenha controle sobre todas as condições e os meios de trabalho postos à sua disposição no espaço institucional.

É relevante salientar que os impactos das atuais configurações do mundo do trabalho se massificam entre os diversos segmentos da classe trabalhadora, com intensidades metamorfoseadas por questões atinentes ao sexo, idade e raça/etnia ${ }^{2}$, as quais, historicamente, têm influenciado nas condições de trabalho dos indivíduos, atribuindo-lhes situações diferenciadas em termos de inserção, permanência e remuneração. A este respeito, Delgado e Aquino (2014, p. 95, grifo dos autores) ressaltam:

A contemporaneidade do capital mundializado, portador de juros e "flexível", reestrutura, na essência, o mercado de trabalho, introduzindo novas e criativas modalidades de contratação e gerenciamento da força de trabalho, com formas caleidoscópicas de trabalho precário, criando novas estratificações e discriminações entre os trabalhadores, com recortes de sexo, etnia, cor da pele e idade.

Dessa feita, ao analisarmos as condições de trabalho para assistentes sociais egressas/os da UERN atentamos para a identificação de algumas informações inerentes ao perfil dos sujeitos que 
estão em exercício profissional. Assim, registramos que as/os assistentes sociais que participaram da pesquisa são predominantemente (96,3\%) do sexo feminino, o que expressa uma característica histórica da profissão, em que as mulheres aparecem como expressiva maioria na composição da categoria. Vale salientar que,

\begin{abstract}
Esse processo é resultante de uma sociedade patriarcal que institui hierarquicamente o que é trabalho/atividade de homens e de mulheres. Por isso, a divisão sexual do trabalho e todas as habilidades, qualidades e características a ela associadas como naturalmente pertencentes aos sexos, deve ser analisada como construção histórica com a nítida reprodução da desigualdade de gênero associada a interesses dominantes. (CISNE, 2012, p. 49).
\end{abstract}

Esse fato explicita um dos motivos pelos quais o Serviço Social não é tão valorizado no mercado de trabalho, não só em termos salariais, mas em relação a diversos outros aspectos, pois a sociedade brasileira machista-patriarcal concede ao gênero masculino uma posição de superioridade e domínio sobre o feminino. $\mathrm{O}$ fato de ser mulher, afeta sobremaneira, segundo Antunes (2000), a intensidade da exploração, as diferenças salariais e a efetivação dos direitos do trabalho em decorrência das desigualdades de gênero.

Quanto à faixa etária, 74,0\% estão entre 21 e 30 anos de idade, $22,3 \%$ estão entre 31 e 40 anos e apenas 3,7\% estão acima dos 50 anos. No que se refere à raça/etnia, nos deparamos com os seguintes dados: $59,2 \%$ identificam-se como de cor branca, $7,5 \%$ de cor preta, e $33,3 \%$ identificaram-se como pardas/os. Isso nos revela a manutenção de um lamentável traço histórico da sociedade brasileira de que, apesar dos avanços, o acesso ao mercado de trabalho ainda é mais difícil para as/os negras/os, notadamente quando se fala em mulheres, o preconceito se acentua.

Um dado de fundamental relevância consiste na distribuição desses profissionais por área de atuação, sobretudo nas políticas públicas, quando se observa que a Assistência Social ocupa o primeiro lugar com 37\%, seguida da Educação com 22,2\%, e em terceiro lugar a área da Saúde com 18,5\%.

Para reforçar essa tendência, outras pesquisas têm demonstrado a política de assistência social como a maior área que emprega assistentes sociais no país, tal como a realizada em Minas Gerais e Rio de Janeiro, entre março de 2008 e julho de 2009, com o total de 989 assistentes sociais formados entre os anos de 2003 e 2007, a 
Iana Vasconcelos | Sâmya Rodrigues Ramos | Aione Maria da Costa Sousa

Kleylenda Linhares da Silva $\mid$ Aline Câmara Macêdo Gracindo

qual aponta que $52 \%$ dos sujeitos respondentes estão atuando nesta área. (DELGADO; AQUINO, 2014).

Tratando-se da natureza das instituições nas quais se inserem os assistentes sociais, observamos que o setor governamental permanece como o maior campo de inserção profissional, com $81,4 \%$, dos quais, $11,1 \%$ atuam na área estadual, $59,2 \%$ na municipal, e $11,1 \%$ na federal. Este grande número de profissionais atuando na área municipal resulta, sobretudo, do processo de descentralização da Política de Assistência Social, com ênfase para sua municipalização, reforçada pela implantação do Sistema Único de Assistência Social (SUAS).

Ressaltamos que a identificação da assistência social como a área que mais emprega assistentes sociais se expressa na contratação pelo setor governamental, principalmente na esfera municipal; bem como na precarização dos vínculos empregatícios e os baixos salários, o que implica instabilidade da permanência e rotatividade dos sujeitos profissionais.

Coadunam com esta reflexão, as informações produzidas em pesquisa acerca do mercado de trabalho de jovens assistentes sociais em Minas Gerais e no Rio de Janeiro, por meio da qual, Delgado e Aquino (2014, p. 103) constataram que "[...] o Estado, no âmbito municipal, tem sido o principal responsável pelos baixos salários pagos aos assistentes sociais”. Então, ao passo que a implantação do SUAS ampliou o mercado de trabalho para as/os assistentes sociais, trouxe consigo formas precarizadas e mal remuneradas de contratação. Situação semelhante é relatada por Santos (2014) com base em pesquisa que desvela as condições e relações de trabalho das/ os assistentes sociais que atuam na política de assistência social nos municípios (com até 20 mil habitantes) do interior do Rio Grande do Norte.

Nesse contexto, as relações de trabalho estabelecidas pelas/ os egressas/os são diversificadas, com predomínio de regime estatutário $(44,4 \%)$, seguidos de $14,8 \%$ que são regidos pela Consolidação das Relações de Trabalho (CLT). É significativo o número de profissionais cujos vínculos empregatícios são instáveis, tal como afirmam 33,4\% destas/es, as/os quais trabalham mediante contratos temporários. 
As formas de seleção que permearam a inserção no local de trabalho também são diferenciadas e demonstram a situação de instabilidade presente na realidade de parte significativa das/os egressos/as, visto que menos da metade $(44,4 \%)$ foi contratada/o a partir de concurso público e $48,2 \%$ tiveram sua inserção baseada em outras formas de seleção. Também foi registrada uma contratação $(3,7 \%)$ por meio de indicação e outra situação $(3,7 \%)$ em que a seleção ocorreu mediante pregão.

Embora os dados desta pesquisa demonstrem a existência de recentes contratações, estas ocorrem de forma restrita, pois não se dão em quantidade suficiente para atender às demandas dos serviços. Desse modo, há um contingente de assistentes sociais que não consegue se inserir no mercado de trabalho, bem como em alguns espaços socioinstitucionais, a despeito das demandas, inexistem estes profissionais nas equipes ou a quantidade destas/es é insuficiente, o que impacta desfavoravelmente na assistência prestada à população e gera sobrecarga para as/os contratadas/os. Isto pode ser visualizado a partir das informações relacionadas à existência de demanda para novas contratações.

Ao abordarmos a necessidade ou não de ampliação do quadro de assistentes sociais na instituição, a maioria (74\%) respondeu que existe essa necessidade, $18,5 \%$ consideram desnecessário e 7,5\% não responderam. A maior parcela dos profissionais admite tal necessidade, especialmente, por questões relacionadas à sobrecarga de trabalho e a excessiva demanda institucional, (Tal) como demonstra a seguinte fala de uma profissional que participou da pesquisa: "[...] porque as duas profissionais não contemplam todas as demandas postas, o que interfere na qualidade dos serviços prestados à população usuária e sobrecarrega o profissional.” (Informação verbal) ${ }^{3}$.

Essa sobrecarga, sem dúvidas, é um dos motivos para levar muitos profissionais ao adoecimento. Isso é comprovado em uma pesquisa com profissionais da saúde que trabalham em unidades de pronto atendimento em Mossoró. "Percebemos que a sobrecarga de trabalho, ocasionada pelos vários vínculos de trabalho, consequência na maioria das vezes dos baixos salários, torna-se um dos principais fatores que contribui para o adoecimento desses trabalhadores." (SILVA, 2015, p. 47).

O trabalho identifica também que esses profissionais lidam com precárias condições de trabalho, e a maioria avalia que sua ati- 
Iana Vasconcelos | Sâmya Rodrigues Ramos | Aione Maria da Costa Sousa

Kleylenda Linhares da Silva $\mid$ Aline Câmara Macêdo Gracindo

vidade profissional influencia no desgaste da sua saúde, principalmente na sua dimensão psíquica.

A maior parte das profissionais que evidenciaram a necessidade de ampliação do número de assistentes sociais (74\%), a justificam por diversos fatores, entre eles, o alto número de demandas que chega ao Serviço Social; o acúmulo de funções; necessidade da presença de assistentes sociais vinte e quatro horas na instituição, sendo este evidenciado por uma profissional da saúde. Outro destaque, ainda, se dá na área da política de assistência social; as profissionais enfatizam que o número de assistentes sociais é insuficiente para responder a todas as demandas que chegam às instituições.

Diante dessa realidade, ressaltamos a importância das lutas da categoria pela efetivação de concursos públicos, mediante o estabelecimento de vínculos de trabalho mais estáveis, fortalecimento da autonomia profissional e arrefecimento da sobrecarga, contribuindo, dessa forma, para a qualidade dos serviços prestados no âmbito das políticas públicas. No caso do pregão, a precarização do trabalho se expressa de forma ainda mais insidiosa, pois expressa a busca incessante pela intensificação da exploração da força de trabalho, no contexto da sociabilidade do capital.

Um depoimento de uma participante da pesquisa é expressivo sobre a necessidade de concurso público: "Precisamos de realização do concurso público que garanta a aquisição de novas profissionais com vínculo efetivo, pois a instabilidade da contratação também incide sobre a saúde psicológica das docentes." (Informação verbal) ${ }^{4}$.

Ao analisar a contrarreforma do Estado brasileiro e suas repercussões no exercício profissional, Guerra ressalta que este assume o enfoque gerencialista, pautado na lógica privatista e no discurso da necessidade de eliminação de privilégios e redução de custos relativos à força de trabalho, de forma que as práticas de gestão são instrumentalizadas, por meio de discursos que expressam necessidades de profissionalização de serviços, ao mesmo tempo se reduz as contratações via concurso público, ampliando os contratos temporários, estando entre eles o via pregão. (GUERRA, 2014).

Ao abordarmos algumas características das relações de trabalho, constatamos que $81,5 \%$ mantêm apenas um vínculo de trabalho como assistente social, e 18,5\% mantêm dois vínculos. No que tange à carga horária semanal, os resultados desta pesquisa demonstraram 
que prevalecem jornadas de trabalho de 30 horas semanais $(48,1 \%)$, como também são praticadas 20 horas em $25,9 \%$ dos contratos e 24 horas em 3,7\%. Contudo, embora a categoria tenha conquistado legalmente a carga horária máxima de 30 horas semanais sem redução salarial, ainda há muitas/os profissionais $(22,3 \%)$ cujos contratos estabelecem jornada de 40 horas. Isto desvela o reincidente desrespeito à Lei das 30 horas semanais sem redução salarial (Lei $\mathrm{n}^{\mathrm{o}} 12.317$, de 26 de agosto de 2010), que foi uma conquista da categoria, originada de lutas e embates, e. que continua em busca de sua materialização nos diversos espaços de trabalho.

Quanto à remuneração, identificamos que a média salarial das/os assistentes sociais equivale a 2.149,60 reais, sendo que $25,9 \%$ recebem salários (líquidos) entre $1.275,00$ a 1.500,00 reais, enquanto o maior valor informado foi 5.211,00 reais. Os salários mais baixos se concentram na esfera pública municipal, com destaque para as instituições que compõem o Sistema Único da Assistência Social; enquanto os mais elevados estão nas instituições federais, particularmente na área da educação.

Essa tendência de baixos salários foi identificada em pesquisa com as/os egressas/os de anos anteriores, entre as/os quais 76,5\% recebiam até três salários mínimos, o que, considerando o valor de referência definido naquele ano, equivale a 1.245 reais. (RAMOS et al., 2008). Esta é uma realidade que perpassa a contratação dos diversos segmentos de trabalhadoras/es no Brasil e afeta também as/os assistentes sociais, conforme evidenciado em pesquisa sobre o perfil dessa categoria no país, realizada pelo Conselho Federal de Serviço Social (CFESS, 2005), na qual a concentração dos menores salários encontra-se na região Nordeste. Essa tendência prevalece também no mercado de trabalho para as/os assistentes sociais em Sergipe, onde há, conforme assinalado por Santos (2010, p.164),

\footnotetext{
[...] um quadro de precarização das condições e relações de trabalho expresso pelo baixo nível dos salários percebidos quando pensados sob a ótica da demanda de trabalho relacionada à quantidade de profissionais que tende a indicar uma sobrecarga de atividades na dinâmica dessas instituições.
}

Destarte, as informações explicitam que, de uma forma geral, as/os assistentes sociais recebem baixos salários, o que reforça a importância da luta do CFESS e Conselhos Regionais de Serviço Social (CRESS) pela garantia de um piso salarial para a categoria, o 
Iana Vasconcelos | Sâmya Rodrigues Ramos | Aione Maria da Costa Sousa

Kleylenda Linhares da Silva $\mid$ Aline Câmara Macêdo Gracindo

que implica a busca de aprovação do Projeto de Lei no 5.278/2009. Por essa razão, Ricardo Antunes, em entrevista para o CFESS, em março de 2016, afirma que:

[...] não basta lutar para se ter um piso. É preciso lutar para que ele seja respeitado. Veja como exemplo professores e professoras do ensino público, que possuem um piso salarial, mas que muitos estados e municípios não cumprem por falta de obrigatoriedade no cumprimento da Lei. Então, o primeiro passo que as assistentes sociais devem dar é conseguir a aprovação de um piso salarial digno. Em seguida, lutar pela sua implementação.

Grande parte das/os egressas/os demonstra compromisso com a formação profissional continuada, pois $74 \%$ finalizaram ou estão cursando especialização em áreas diversas, 33,3\% concluíram ou estão realizando mestrado e $3,7 \%$ estão inseridas/os na residência multiprofissional em saúde. Todas/os afirmaram que participam de cursos, eventos e grupos de estudos, o que expressa o compromisso com o aprimoramento dos seus conhecimentos e com a qualidade dos serviços prestados. Nessa perspectiva, o conjunto CFESS/ CRESS, em articulação com a Associação Brasileira de Ensino e Pesquisa em Serviço Social (ABEPSS) e a Executiva Nacional de Estudantes de Serviço Social (ENESSO), tem proporcionado espaços de formação continuada, tendo como horizonte o fortalecimento do projeto ético-político do Serviço Social.

Assim, a educação permanente se constitui em um importante instrumento para a construção e qualificação de ações cotidianas no exercício da profissão e na sua capacidade de organização política. Dessa forma, é necessário reconhecê-la também como instrumento fundamental de luta política e ideológica. Por esta razão, é que o Conjunto CFESS-CRESS vem privilegiando o espaço da formação, como uma das ferramentas que possibilita o fortalecimento do nosso projeto profissional. (CONSELHO FEDERAL DE SERVIÇO SOCIAL, 2012, p.15-16).

Vale destacar, ainda, que a exigência de capacitação se configura como uma tendência do mercado de trabalho para os diversos segmentos da classe trabalhadora. Tal exigência não tem sido acompanhada do compromisso dos espaços socioinstitucionais em apoiar a formação continuada das/os trabalhadoras/es, fazendo com que, muitas vezes, estas/es assumam individualmente os custos de sua formação continuada e o tempo dedicado a estas atividades extrapole sua jornada de trabalho, podendo interferir também na saúde destes sujeitos devido à sobrecarga. Por outro lado, ao contrário da 
ideia difundida no senso comum, de acordo com Leite (1997), a elevação do nível de escolaridade das/os trabalhadoras/es brasileiras/os e a elevação dos investimentos em educação e formação profissional estão ocorrendo paralelamente ao crescimento do desemprego, à intensificação da precarização do emprego e ao rebaixamento salarial. Para a referida autora,

[...] a educação não pode resolver problemas que fogem da sua alçada, como o da crescente utilização de uma tecnologia altamente poupadora de mão-de-obra no quadro de um modelo de desenvolvimento baseado em relações de trabalho autoritárias e em relações de produção centradas na busca do lucro e na concentração do capital. (LEITE, 1997, p.65).

É perceptível, ainda, que as condições adequadas do espaço físico no qual se efetiva o trabalho é fundamental para viabilizar um atendimento de boa qualidade as/aos usuárias/os, bem como para garantir o direito destas/es profissionais de terem asseguradas condições adequadas de trabalho. Nessa perspectiva, o conjunto CFESS/ CRESS vem construindo diversas estratégias de luta em defesa da qualidade do trabalho profissional, dentre as quais, destacamos a Resolução do CFESS no 493, de 21 de agosto de 2006, a qual estabelece que o órgão empregador deve propiciar condições éticas e técnicas para garantir a qualidade do exercício profissional, de forma que, em seu artigo $2^{\circ}$, define:

O local de atendimento destinado ao assistente social deve ser dota-
do de espaço suficiente, para abordagens individuais ou coletivas,
conforme as características dos serviços prestados, e deve possuir e
garantir as seguintes características físicas: a- iluminação adequa-
da ao trabalho diurno e noturno, conforme a organização institu-
cional; b- recursos que garantam a privacidade do usuário naquilo
que for revelado durante o processo de intervenção profissional;
c- ventilação adequada a atendimentos breves ou demorados e com
portas fechadas; d- espaço adequado para colocação de arquivos
para a adequada guarda de material técnico de caráter reservado.
(CONSELHO FEDERAL DE SERVIÇO SOCIAL, 2006, art. $2^{\circ}$ ).

No que se refere aos espaços físicos disponíveis nos locais onde as/os egressas/os trabalham, a maior parte (59,3\%) não dispõe de uma sala de atendimento específica para o Serviço Social, informação ratificada pela resposta de $63 \%$ delas/es ao afirmarem que utilizam uma sala de atendimento em conjunto com outras/os profissionais. Esta tem se apresentado como uma situação recorrente nos espaços sócio-ocupacionais, nos quais muitas vezes as/os assistentes 
Iana Vasconcelos | Sâmya Rodrigues Ramos | Aione Maria da Costa Sousa

Kleylenda Linhares da Silva $\mid$ Aline Câmara Macêdo Gracindo

sociais dividem o mesmo recinto com psicólogos, enfermeiros, pedagogos e outras/os trabalhadoras/es de diversas áreas. A despeito da importância de espaços que possibilitem a efetivação do trabalho conjuntamente com outras/os profissionais e das estratégias de revezamento na utilização destas salas comumente praticada pela equipe, o fato de haver uma única sala de trabalho que é coletiva pode dificultar a garantia do sigilo profissional e a qualidade do atendimento.

Quanto às condições da sala em que $\mathrm{a} / \mathrm{o}$ assistente social efetiva o atendimento às/aos usuárias/os, foi possível identificar que em vários locais ocorrem dificuldades na garantia do sigilo, haja vista que $29,6 \%$ dos sujeitos consideram que esses espaços não propiciam o caráter sigiloso nos atendimentos.

\begin{abstract}
Embora a manutenção do sigilo seja um direito do assistente social, muitas vezes o respeito a tal garantia é violado pelas condições e estrutura do ambiente de trabalho, da estrutura física da sala onde está instalado o Serviço Social, que por vezes não veda o som e está instalada em lugar impróprio, inadequado, de acesso a terceiros, como assistimos no cotidiano da atividade profissional. (BARROCO; TERRA, 2012, p. 206).
\end{abstract}

Reforçando essa realidade, um percentual significativo $(25,9 \%)$ de egressas/os avalia que a sala não garante a privacidade no atendimento das/os usuárias/os. Vale salientar também que 40,7\% consideram que a sala não possui condições físicas favoráveis. Isso expressa o sucateamento dos espaços socioinstitucionais causado, dentre outros fatores, pelo insuficiente investimento nas políticas públicas, intensificado pelo projeto neoliberal hegemônico no cotidiano da vida social no Brasil, a partir de 1990.

A partir dessa realidade, destacamos que a luta por melhores condições de trabalho precisa ser constantemente encampada pelas/ os profissionais em seus espaços de atuação, de forma articulada com as entidades organizativas da categoria e com outros sujeitos (profissionais, usuárias/os e outros segmentos trabalhadores) comprometidos com a defesa da qualidade dos serviços.

Aspecto importante a ser analisado é que o trabalho da/o assistente social, comumente, requer o estabelecimento de relações com outros serviços, inclusive para proceder ao encaminhamento de usuárias/os, de modo que o contato telefônico é fundamental, bem como a disponibilidade de transporte para a realização de visitas institucionais e domiciliares. Contudo, identificamos que em parte das 
instituições empregadoras não tem telefone, pois este aparelho não está disponível em 37\% dos locais de trabalho. Quanto ao transporte, a dificuldade é ainda maior, pois somente existem veículos disponíveis em $55,6 \%$ das unidades.

Ressaltamos que as condições e relações de trabalho estabelecem estreita interface com a situação de saúde-adoecimento das/os trabalhadoras/es, de maneira que o atual contexto de intensificação da exploração da força de trabalho é marcado pelo crescimento da incidência/identificação de doenças relacionadas às vivencias laborais. Nesse sentido, Raichelis (2011, p. 421) evidencia:

$$
\begin{aligned}
& \text { Em um contexto societário de transformações no trabalho de tal } \\
& \text { monta, marcado pela retração e, mesmo, pela erosão do trabalho } \\
& \text { contratado e regulamentado, bem como dos direitos sociais e tra- } \\
& \text { balhistas, ampliam-se também as relações entre trabalho e adoeci- } \\
& \text { mento, repercutindo na saúde física e mental dos trabalhadores, nas } \\
& \text { formas de objetivação e subjetivação do trabalho. }
\end{aligned}
$$

$\mathrm{O}$ adoecimento relacionado ao trabalho tem se manifestado também entre as/os assistentes sociais, muito embora ainda sejam escassos os estudos acerca dessa problemática. Diante disso, as/os profissionais foram indagadas/os, ainda, acerca da interface entre $o$ seu trabalho e suas condições de saúde, resultando que $66,7 \%$ afirmaram que existe relação, $18,5 \%$ disseram que não existe associação e $14,8 \%$ não souberam informar.

Compreendemos que o processo saúde-adoecimento resulta da interação entre uma multiplicidade de fatores de cunho biológico, psíquico, social, econômico, político e cultural, sendo, portanto, influenciado pelas condições de vida e trabalho dos indivíduos, as quais são determinadas pela forma de organização das relações sociais. De acordo com Albuquerque e Silva (2014, p. 960), "Em sociedades de classes, as relações que se estabelecem entre as classes determinam diferentes possibilidades e restrições ao desenvolvimento da vida e, consequentemente, diferentes formas ou possibilidades de viver, adoecer e morrer".

Com efeito, na sociedade capitalista em particular, o trabalho é permeado por relações de exploração e alienação, o que o torna, muitas vezes, desencadeador ou intensificador de desgaste da saúde, não obstante se configure fator indispensável para se ter acesso às condições de subsistência, propiciadoras da saúde. Nesse contexto, embora seja frequente o adoecimento relacionado ao trabalho, sua 
Iana Vasconcelos | Sâmya Rodrigues Ramos | Aione Maria da Costa Sousa

Kleylenda Linhares da Silva $\mid$ Aline Câmara Macêdo Gracindo

ocorrência nem sempre é registrada e reconhecida, devido a fatores como a subnotificação e a complexa identificação/comprovação de nexos causais entre as experiências laborais e o desgaste da saúde, haja vista que as/os trabalhadoras/es convivem, simultaneamente, com diversas determinações que afetam à população em geral, conjuntamente com aspectos intrínsecos ao trabalho. Além disso, alguns processos de adoecimentos se desenvolvem lenta e silenciosamente, o que também dificulta o desvelamento desta relação. (ROSADO; RUSSO; MAIA, 2015). Cogitamos que isto pode ter influenciado nas respostas dos sujeitos a este questionamento, especialmente entre os que evidenciaram que não sabem avaliar se existe ou não tal relação.

Concernente à relação entre o trabalho efetivado e a situação de saúde dos sujeitos, embora alguns $(18,5 \%)$ a definam como inexistente e outros $(14,8 \%)$ não saibam avaliar se esta sucede, predominou $(66,7 \%)$ o entendimento acerca da existência desta relação, principalmente $(51,8 \%)$ no sentido da atividade laboral influenciar desfavoravelmente à saúde. Por outro lado, parte das/os assistentes sociais $(11,1 \%)$ visualizam esta relação no sentido de o trabalho favorecer a saúde, por se realizar em um ambiente com condições materiais e estruturais salubres e por haver uma boa relação entre as/ os profissionais. É importante salientar, ainda, que 3,7\% ressaltam que esta relação se dá nos dois sentidos, conforme alguns relatos:

\begin{abstract}
As boas condições de trabalho contribuem para que me sinta bem mentalmente e também realizada no que faço. Por outro lado, ao trabalhar 40 horas diárias e muito desse tempo dá-se sentada acaba que me sinto bastante sedentária e tenho pouco tempo para a prática de exercício físico, o que traz implicações na minha saúde física. (Informação verbal) ${ }^{5}$.
\end{abstract}

As/os que avaliam que o trabalho traz prejuízos para a saúde citaram alguns determinantes deste processo, dentre os quais se destaca o estresse gerado pelas condições precárias de trabalho, tal como registrado por uma/um delas/es: "Porque os conflitos gerados por esta falta de condição de trabalho, termina causando um estresse quase que rotineiro, e isso influencia demais minha saúde, principalmente psicológica". (Informação verbal) ${ }^{6}$.

Foram enfocadas também a alta demanda e sobrecarga de trabalho, como fatores que dificultam a disponibilidade de tempo para o lazer e o descanso. A instabilidade dos contratos, a falta de valori- 
CONDIÇÕES DE TRABALHO E SAÚDE DE ASSISTENTES SOCIAIS NO ÂMBITO DAS POLÍTICAS PÚBLICAS

zação, os baixos salários, o acúmulo de vínculos, e a consequente intensificação da jornada de trabalho foram também apontados como fatores de desgaste da saúde. Nos termos das/os assistentes sociais:

Outro aspecto que contribui significativamente para o nosso adoecimento psicológico, além da sobrecarga de trabalho, é a instabilidade de nosso vínculo [...]

As transformações ocorridas no mundo do trabalho nas últimas décadas têm repercutido na saúde da classe trabalhadora. Vale destacar que a intensificação do trabalho é traço característico da atual fase do capitalismo e tem levado cada vez mais ao consumo desmedido das energias físicas e espirituais dos trabalhadores. Outro ponto importante é a insegurança gerada pelo medo do desemprego, fazendo com que os profissionais se submetam a contratos de trabalhos precários, recebendo baixos salários e arriscando suas vidas e prejudicando sua saúde em ambientes insalubres. (Informação verbal) $)^{7}$.

Os relatos supracitados evidenciam que as/os egressas/os, acompanhando uma tendência vivenciada pela classe trabalhadora e, por conseguinte, pelas/os assistentes sociais, têm incorporado amplas jornadas de trabalho, marcadas pelo pluriemprego, pelos baixos salários e pela instabilidade das formas de contratação, com influxos na situação de saúde destes sujeitos. Ao analisar essa tendência do acúmulo de vínculos de trabalho entre assistentes sociais, Guerra (2014, p. 50) enfatiza:

Há ainda, a inserção sócio-profissional em duas ou mais políticas sociais, uma rotatividade inédita, resultante dos vínculos instáveis e dos baixos salários, além da intensificação e extensão de carga horária por ter que cumprir, pelo menos, duas jornadas de traba1ho. Numa profissão com quase $99 \%$ de mulheres, a tendência do pluriemprego, da intensificação do trabalho e do sobretrabalho doméstico, limita a possibilidade de investimento da capacitação e na pesquisa, mais ainda, no necessário tempo de lazer e descanso, levando cada vez mais ao stress e adoecimento.

Igualmente, as/os egressas/os registraram que o trabalho se torna desgastante para a saúde devido ao fato de se depararem, na dinâmica institucional, com algumas demandas que não são passíveis de resolução por parte destas profissionais pela situação de sucateamento das políticas públicas. "Trabalhar com a política de saúde pública e suas limitações já é um desafio [...]. O cotidiano da urgência e emergência é estressante e acabamos absorvendo isso e 
Iana Vasconcelos | Sâmya Rodrigues Ramos | Aione Maria da Costa Sousa

Kleylenda Linhares da Silva $\mid$ Aline Câmara Macêdo Gracindo

prejudicando a nossa própria saúde (física e mental)". (Informação verbal $)^{8}$.

$\mathrm{Na}$ área da política de saúde, Soares (2014) identifica níveis de impacto nas condições de trabalho de assistentes sociais no contexto da contrarreforma. Um deles refere-se à contratação da categoria que se efetiva devido ao crescimento de demandas, ficando esta "[...] limitada pelo próprio conteúdo da política e de sua racionalidade hegemônica. De forma que, mesmo aumentando o número desses profissionais no SUS, o déficit de assistentes sociais persiste." (SOARES, 2014, p.209). Acrescenta-se que convivemos com "[...] a superexploração e precarização das condições de trabalho. Tendo em vista que um dos importantes fundamentos da racionalidade da contrarreforma tem sido a reestruturação da gestão do trabalho." (SOARES, 2014, p. 210-211).

Essa realidade da política de saúde insere-se no contexto mais amplo de sucateamento das políticas públicas, intensificado, no Brasil, no contexto neoliberal no qual

A tendência geral tem sido a de restrição e redução de direitos, sob o argumento da crise fiscal do Estado, transformando as políticas sociais [...] em ações pontuais e compensatórias direcionadas para os efeitos mais perversos da crise [...] prevalecendo o já referido trinômio articulado do ideário neoliberal para as políticas sociais, qual seja: a privatização, a focalização e a descentralização. (BEHRING; BOSCHETTI, 2006, p. 156).

O conjunto dos problemas elencados, segundo as profissionais, afeta a saúde nas dimensões física e mental, gerando cansaço mental/crônico, estresse, estafa, ansiedade, nervosismo. Além disso, as que trabalham na área da saúde, em particular, registram o risco de contrair doenças ao lidar com pessoas enfermas.

Essa realidade aprofunda os desafios postos à classe trabalhadora e, como parte desta, as/aos assistentes sociais, que se deparam com as situações de precarização das condições do seu trabalho, ao mesmo tempo que lidam com as adversidades no enfrentamento das expressões da questão social, agravadas no atual contexto, o que também gera influxos no sofrimento e adoecimento de tais sujeitos. De acordo com Raichelis (2011, p. 434-435),

Trata-se de uma condição de trabalho que produz um duplo processo contraditório nos sujeitos assistentes sociais: a) de um lado, o prazer diante da possibilidade de realizar um trabalho compro- 
metido com os direitos dos sujeitos violados em seus direitos, na perspectiva de fortalecer seu protagonismo político na esfera pública; b) ao mesmo tempo, o sofrimento, a dor, o desalento diante da exposição continuada à impotência frente à ausência de meios e recursos que possam efetivamente remover as causas estruturais que provocam a pobreza e a desigualdade social.

Essas expressões se intensificam, no âmbito da categoria, em decorrência da elevada composição feminina, de forma que a análise acerca das condições de trabalho das/os assistentes sociais requer considerar as desigualdades que permeiam a divisão sexual do trabalho no âmbito da sociedade capitalista-patriarcal, pois, segundo Cisne (2013, p. 44), "[...] negar a dimensão de sexo no trabalho é negar a realidade em que vive a classe trabalhadora, em especial a das mulheres, em sua relação com o capital". Tal discussão também se faz necessária para analisar os influxos do trabalho na saúde destas/es trabalhadoras/es, haja vista que as desigualdades vivenciadas pelas mulheres no mercado de trabalho se somam às disparidades na distribuição do trabalho doméstico, que as sobrecarrega com o acúmulo de múltiplas tarefas vinculadas à reprodução social e se refletem em uma jornada extenuante de trabalho (remunerado e não remunerado).

\section{CONCLUSÃO}

Diante dessa realidade, ressaltamos que as situações vivenciadas pelas/os assistentes sociais devem ser analisadas em uma perspectiva de totalidade que contemple os processos societários contemporâneos e seus rebatimentos para a classe trabalhadora, dentre os quais, a intensificação do adoecimento relacionado ao trabalho.

Assim, o atual contexto societário, marcado pela reestruturação do capital alicerçada na redefinição dos processos de gestão e organização do trabalho e do modelo de atuação do Estado, impulsiona alterações nas demandas postas à profissão, bem como nas condições e relações de trabalho nas quais o exercício profissional se efetiva.

Dessa forma, a/o assistente social, que não detém todos os meios necessários à efetivação do seu trabalho, lida, cotidianamente e em conjunto com outras/os trabalhadoras/es, no âmbito das políticas públicas, com determinações impostas pela precariedade das 
Iana Vasconcelos | Sâmya Rodrigues Ramos | Aione Maria da Costa Sousa

Kleylenda Linhares da Silva $\mid$ Aline Câmara Macêdo Gracindo

condições de trabalho que permeiam a efetivação dos processos de trabalho coletivo dos quais são partícipes.

Assim, o mercado de trabalho para as/os assistentes sociais egressas/os da Universidade do Estado do Rio Grande do Norte é marcado por ampla utilização de formas instáveis de contratação, baixos salários e adversidades em termos de condições de trabalho.

Destarte, ressaltamos a importância das lutas da categoria por melhores condições de trabalho e pela efetivação de concursos públicos, fundamentais para o estabelecimento de vínculos de trabalho mais estáveis e melhores condições em termos de autonomia profissional, com influxos na qualidade do trabalho e na saúde das/os profissionais.

\section{REFERÊNCIAS}

ALBUQUERQUE, G. S. C. de; SILVA, M. J. S. e. Sobre a Saúde, os determinantes da Saúde e a determinação social da saúde. Saúde em Debate, Rio de Janeiro, v. 38, n. 103, p. 953-965, out./dez. 2014. Disponível em:<http://www.scielo.br/pdf/sdeb/v38n103/0103-1104sdeb-38-103-0953.pdf >. Acesso em: 19 ago. 2016.

ANTUNES, R. Os sentidos do trabalho: ensaios sobre a afirmação e a negação do trabalho. São Paulo: Boitempo, 2000.

. Luta em unidade da classe trabalhadora é fundamental para aprovar piso salarial. Conselho Federal de Serviço Social, Brasília, DF, 28 de março de 2016. Entrevista. Não paginado. Disponível em: $<$ www.cfess.org.br/visualizar/noticia/cod/1249>. Acesso em: 19 ago. 2016.

BARROCO, M. L. S.; TERRA, S. H. (Orgs.). Código de ética do/a Assistente Social comentado. São Paulo: Cortez, 2012.

BEHRING, E.; BOSCHETTI, I. Política Social: fundamentos e história. São Paulo: Cortez, 2006. (Biblioteca Básica de Serviço Social, v. 2).

CISNE, M. Gênero, divisão sexual do trabalho e Serviço Social. São Paulo: Outras Expressões, 2012.

. Feminismo, luta de classes e consciência militante feminista no Brasil. 2013. Tese (Doutorado em Serviço Social) - Universidade do Estado do Rio de Janeiro, Rio de Janeiro, 2013. 
CONSELHO FEDERAL DE SERVIÇO SOCIAL (Org). Assistentes Sociais no Brasil: elementos para o estudo do perfil profissional. Brasília, DF, 2005.

Política de educação permanente do Conjunto CFESSCRESS. Brasília, DF, 2012.

Resolução n ${ }^{\circ} 493$, de 21 de agosto de 2006. Dispõe sobre as condições éticas e técnicas do exercício profissional do assistente social. Brasília, DF, 2006.

DELGADO, L. B.; AQUINO, I. G. de C. O mercado (precarizado) de trabalho do Assistente Social em Minas Gerais e no Rio de Janeiro: condições de contratação, remuneração e salários indiretos. In: MORJO, Carina B.; SANTOS, Cláudia M (Orgs.). Serviço Social e Questão Social: Implicações no mundo do trabalho e no exercício profissional do assistente social em Juiz de Fora. Juiz de Fora: Ed. UFJF, 2014. p. 93-110.

DIAS, E. A liberdade (im)possível na ordem do capital: reestruturação produtiva e passivização. Campinas, SP: EDIFCH/UNICAMP, 1997.

GUERRA, Y. Transformações societárias e Serviço Social: repercussões na cultura profissional. In: MOTA, A. E.; AMARAL, A. (Orgs.). Serviço Social brasileiro nos anos 2000: cenários, pelejas e desafios. Recife: EDUFPE, 2014. p. 45-62.

IAMAMOTO, M. V. As Dimensões Ético-Políticas e TeóricoMetodológicas no Serviço Social Contemporâneo. In: MOTA, A. E. et al. (Orgs). Serviço Social e saúde: formação e trabalho profissional. São Paulo: OPAS, OMS, Ministério da Saúde, 2006. p. 161-196.

LEITE, M. de P. Qualificação, desemprego e empregabilidade. São Paulo em Perspectiva, São Paulo, n. 11, 1997.

PAIVA, A. S. de; COSTA, M. D. H. da. Ataques à política de saúde em tempos de crise do capital. Revista de Políticas Públicas, São Luís, v. 20, n. 1, p. 51-68, jan./jun. 2016. Disponível em: $<$ http://www. periodicoseletronicos.ufma.br/index.php/rppublica/article/view/5036>. Acesso em: 30 ago. 2016.

RAMOS, S. R. et al. Tendências do Mercado de Trabalho para Assistentes Sociais egressos da Universidade do Estado do Rio Grande do Norte: demandas, condições de trabalho e materialização do projeto ético político profissional. Natal: UERN, 2008. Relatório de Pesquisa. 
Iana Vasconcelos | Sâmya Rodrigues Ramos | Aione Maria da Costa Sousa

Kleylenda Linhares da Silva $\mid$ Aline Câmara Macêdo Gracindo

RAICHELIS, R. O assistente social como trabalhador assalariado: desafios frente às violações de seus direitos. Serviço Social e Sociedade, São Paulo, n. 107, p. 420-437, 2011.

ROSADO, I. V. M.; RUSSO, G. H. A.; MAIA, E. M. C. Produzir saúde suscita adoecimento?: as contradições do trabalho em hospitais públicos de urgência e emergência. Ciência e Saúde Coletiva, Rio de Janeiro, v. 20, ano 10, p. 3021-3032, 2015. Disponível em:<www. scielo.br/pdf/csc/v20n10/1413-8123-csc-20-10-3021.pdf >. Acesso em: 30 ago. 2016.

SANTOS, M. B. J. dos. A expansão e interiorização das competências profissionais na política de Assistência Social do Rio Grande do Norte. In: MOTA, A. E.; AMARAL, A. (Orgs.). Serviço Social brasileiro nos anos 2000: cenários, pelejas e desafios. Recife: EDUFPE, 2014. p. 151-176.

, S. M. de M. O CFESS na defesa das condições de trabalho e do projeto ético-político profissional. Serviço Social e Sociedade, São Paulo, n. 104, p. 695-714, out./dez. 2010.

SILVA, E. N. O processo saúde-adoecimento dos assistentes sociais que atuam em unidades de pronto atendimento em Mossoró-RN. 2015. Monografia (Graduação) - Faculdade de Serviço Social, Universidade do Estado do Rio Grande do Norte, Mossoró, 2015.

SOARES, R. C. Contrarreforma na política de saúde e prática profissional do Serviço Social nos anos 2000. In: MOTA, A. E.; AMARAL, A. (Orgs). Serviço Social brasileiro nos anos 2000: cenários, pelejas e desafios. Recife: EDUFPE, 2014. p. 201-226.

\section{Notas}

Segundo Dias (1997, p. 14), “[...] todo o processo conhecido como reestruturação produtiva nada mais é do que a permanente necessidade de resposta do capital às suas crises. Para fazerlhes frente é absolutamente vital ao capital - e aos capitalistas - redesenhar não apenas sua estruturação 'econômica', mas, sobretudo, reconstruir permanentemente a relação entre as formas mercantis e o aparato estatal que lhe dá coerência e sustentação.

2 Estas dimensões do ser social devem ser consideradas na análise das condições e relações de trabalho vivenciadas pelos sujeitos desta pesquisa devido à maciça presença feminina na profissão que igualmente se evidencia entre as/os egressas/os participantes. Outros aspectos tais como a condição física, a orientação sexual, também perpassam as relações de trabalho, mas não serão passíveis de análise nos limites deste artigo.

3 Depoimento de uma participante da pesquisa.

4 Depoimento de uma participante da pesquisa.

Depoimento de uma participante da pesquisa.

Depoimento de uma participante da pesquisa.

Depoimento de uma participante da pesquisa.

8 Depoimento de uma participante da pesquisa. 